OPEN ACCESS

Edited by:

Rafael T. Mikolajczyk,

National Research Centre for

Biotechnology, Germany

Reviewed by:

Christiane Stock,

University of Southern Denmark,

Denmark

Rubeena Zakar,

University of the Punjab, Pakistan

Ana Pilar Betrán,

World Health Organization,

Switzerland

*Correspondence:

Edward Broughton

ebroughton@urc-chs.com

Specialty section:

This article was submitted

to Population, Reproductive

and Sexual Health,

a section of the journal

Frontiers in Public Health

Received: 03 June 2016

Accepted: 24 October 2016

Published: 21 November 2016

Citation:

Broughton E, Hermida J, Hill K, Sloan N, Chavez M, Gonzalez D, Freire JM and Gudino X (2016) Evaluation of an Intervention to Improve Essential Obstetric and

Newborn Care Access and

Quality in Cotopaxi, Ecuador.

Front. Public Health 4:247.

doi: 10.3389/fpubh.2016.00247

\section{Evaluation of an Intervention to Improve Essential Obstetric and Newborn Care Access and Quality in Cotopaxi, Ecuador}

\author{
Edward Broughton ${ }^{1,2 *}$, Jorge Hermida ${ }^{1}$, Kathleen Hill ${ }^{3}$, Nancy Sloan ${ }^{4}$, Mario Chavez $^{5}$, \\ Daniel Gonzalez ${ }^{6}$, Juana Maria Freire ${ }^{7}$ and Ximena Gudino ${ }^{1}$ \\ 1 University Research Co., LLC, Bethesda, MD, USA, ${ }^{2}$ Johns Hopkins School of Public Health, Baltimore, MD, USA, \\ ${ }^{3}$ Jhpiego, Washington, DC, USA, ${ }^{4}$ Independent Contractor, New York, NY, USA, ${ }^{5}$ Ministerio de Salud, Quito, Ecuador, \\ ${ }^{6}$ Ministerio de Cultura, Quito, Ecuador, ${ }^{7}$ Universidad San Francisco de Quito, Quito, Ecuador
}

Background: Despite improvements in health-care utilization, disadvantages persist among rural, less educated, and indigenous populations in Ecuador. The United States Agency for International Development-funded Cotopaxi Project created a provincial-level network of health services, including community agents to improve access, quality, and coordination of essential obstetric and newborn care. We evaluated changes in participating facilities compared to non-participating controls.

Methods: The 21 poorest parishes (third-level administrative unit) in Cotopaxi were targeted from 2010 to 2013 for a collaborative health system performance improvement. The intervention included service reorganization, integration of traditional birth attendants (TBAs) with formal supervision, community outreach and education, and health worker technical training. Baseline $(n=462)$ and end-line $(n=412)$ household surveys assessed access, quality and use of care, and women's knowledge and practices. TBAs' knowledge and skills were assessed from simulations. Chart audits were used to assess facility obstetric and newborn care quality. Provincial government data were used for change in neonatal mortality between intervention and non-intervention parishes using weighted linear regression.

Results: The percentage of women receiving a postnatal visit within first 2 days of delivery increased from 53 to 81 in the intervention group and from 70 to 90 in the comparison group $(p \leq 0.001)$. Postpartum/counseling on newborn care increased $18 \%$ in the intervention compared with $5 \%$ in the comparison group $(p \leq 0.001)$. The project increased community and facility care quality and improved mothers' health knowledge. Intervention parishes experienced a nearly continual decline in newborn mortality between 2009 and 2012 compared with an increase in control parishes ( $p \leq 0.001$ ).

Conclusion: The project established a comprehensive coordinated provincial-level network of health services and strengthened links between community, primary, and hospital health care. This improved access to, quality, use, and provision of essential obstetric and neonatal care and survival. Ecuador's Ministry of Health is scaling up the model nationally.

Keywords: essential obstetric and newborn care, quality of care, neonatal mortality, Ecuador 


\section{INTRODUCTION}

In Ecuador, the institutional deliveries increased from $74 \%$ between 2000 and 2006 to $85 \%$ between 2007 and 2012. However, there remains lower use of maternal newborn services among the rural, poor, and indigenous population. A recent national maternal and child health survey showed that $37 \%$ of indigenous women did not receive four antenatal care (ANC) visits and only $30 \%$ had skilled delivery attendance in rural areas compared with 13 and $80 \%$ of Mestizo (non-indigenous) women, respectively. Only $15 \%$ compared with $38 \%$ received postpartum care, respectively (1). This disparity is partly attributable to a public health-care system that preferentially offered more skilled care to larger urban populations in provincial and county capitals. In 2009, the two largest public health providers, the Ministry of Health $(\mathrm{MOH})$ and the Social Security Institute, offered ANC to the rural population through parish (sub-county) health centers with daytime but no night time, holiday, or weekend services. The majority of institutional deliveries are attended at district or provincial hospitals. Since most indigenous Ecuadoreans reside in rural parishes, difficult access to care and cultural preferences resulted in them receiving maternal and newborn health care from traditional birth attendants (TBAs), traditional healers, and family members.

Improving access and service quality from household to hospital across the continuum of antenatal to postpartum care is necessary to improve maternal and neonatal survival (2-5). The MOH's quality improvement (QI) program has been committed to improving essential obstetric and newborn care (EONC) since 2003 (6). However, coordination with the private sector and community mobilization are critical to increase appropriate, timely access to essential care (7-9). To overcome geographic, transportation, financial, service readiness, and cultural gaps at the root of disparities in EONC access and use among rural, indigenous, and poor populations, the Center for Human Services (CHS) implemented a project in Cotopaxi from September 2009 to September 2013, supported by the Child Survival and Health Grants Program of the United States Agency for International Development (USAID).

Cotopaxi is one of Ecuador's 24 provinces, located in the central highlands, and includes 7 counties and 33 rural parishes served by the MOH's provincial referral hospital, 4 district hospitals and 20 parish health centers, 1 Social Security hospital, some ambulatory health centers, and 1 non-governmental organization (NGO) rural hospital. About 270 TBAs operating, there have historically been isolated from the formal health-care system. In 2008 , the province had 384,500 inhabitants: $67 \%$ were rural, $28 \%$ were indigenous, and $90 \%$ were poor, with little access to or use of formal maternal newborn services (10). The project's baseline survey found $49 \%$ of indigenous compared with $77 \%$ of Mestizo mothers made four or fewer ANC visits and 36\% compared with $89 \%$ delivered in a health facility. At that time, there was little vertical coordination across the four health services levels (community care, parish ambulatory health centers, county hospitals, and the provincial hospital). There was also no horizontal coordination between public and private providers and other institutions which generally worked in isolation.
This lack of coordination and the marginalization of TBAs were barriers to effective care with dysfunctional referral mechanisms, particularly for the poorer, indigenous, and rural population.

This study evaluated changes in facilities participating in the EONC network created by USAID's Cotopaxi Project in terms of access and quality indicators of EONC and compared to nonparticipating facilities.

\section{MATERIALS AND METHODS}

The project's aims were to improve access to and quality of EONC across the care continuum by creating a provincial-level network to coordinated maternal newborn health services and strengthened linkages between levels of care (Table 1). The project targeted 21 parishes with more than half the population in extreme poverty or more than $40 \%$ indigenous residents. The project was conducted collaboratively with national, regional, and local partners including the $\mathrm{MOH}$, Social Security Institute, the Peasant Social Security Program, various NGOs, and local community organizations.

\section{Intervention}

The intervention commenced in 2011 in Pujilí county's parishes and in Salcedo, Saquisilí, and Sigchos counties' parishes in 2012. The network engaged previously isolated and competitive health services in a collaborative effort to improve service provision and utilize culturally sensitive, quality EONC, including referral and

\begin{tabular}{|c|c|}
\hline Aim & Project intervention \\
\hline $\begin{array}{l}\text { Strengthen } \\
\text { support for } \\
\text { the EONC } \\
\text { network }\end{array}$ & $\begin{array}{l}\text { Engage local parish and municipal government representatives } \\
\text { to promote awareness of and adherence to national laws } \\
\text { mandating coordinated service provision through a public } \\
\text { health-care system }\end{array}$ \\
\hline $\begin{array}{l}\text { Improve } \\
\text { availability of } \\
\text { EONC health } \\
\text { services }\end{array}$ & $\begin{array}{l}\text { - Services in the provincial and five county hospitals were } \\
\text { organized to ensure } 24 / 7 \text { availability of EONC } \\
\text { - Services were expanded by reorganizing provider work hours } \\
\text { and by training and supervising all providers of obstetric and } \\
\text { newborn care }\end{array}$ \\
\hline $\begin{array}{l}\text { Increase } \\
\text { demand } \\
\text { for EONC } \\
\text { services }\end{array}$ & $\begin{array}{l}\text { - A weekly radio program was aired in Spanish and Kechwa. The } \\
\text { radio program was about healthy behaviors, danger signs, and } \\
\text { seeking professional care }\end{array}$ \\
\hline $\begin{array}{l}\text { Increase use } \\
\text { and access } \\
\text { of EONC } \\
\text { services }\end{array}$ & $\begin{array}{l}\text { - Emergency community transportation committees were } \\
\text { organized in several parishes } \\
\text { - The network formally integrated TBAs and community } \\
\text { health workers (CHWs) to provide essential linkages with the } \\
\text { community } \\
\text { - TBAs and CHWs were trained to identify maternal and } \\
\text { newborn danger signs and risk factors and to refer them to } \\
\text { health centers }\end{array}$ \\
\hline $\begin{array}{l}\text { Improve the } \\
\text { quality of } \\
\text { EONC care }\end{array}$ & $\begin{array}{l}\text { - } \mathrm{MOH} \text { referral protocols were updated, and personnel were } \\
\text { trained during a 4-day one-time training activity aimed at } \\
\text { developing EONC knowledge and skills } \\
\text { - The network established and supported QI teams comprised of } \\
\text { parish health center staff, CHWs, and TBAs who met monthly } \\
\text { to work on improving access and quality of EONC services }\end{array}$ \\
\hline
\end{tabular}


transportation of obstetric and newborn emergencies. In order to engage local parish and municipal government representatives to promote awareness of and adherence to national laws mandating coordinated service provision through a public health-care system, the project organized several meetings where such laws and national priorities were discussed. Emergency community transportation committees were organized in several parishes. These were responsible for notifying health facilities of patient referrals and requesting transport of emergency cases by ambulances which were present at all district/county hospitals in the province. Services in the provincial and five county hospitals were organized to ensure 24/7 availability of EONC for all women and newborns through labor, delivery, and the early postpartum period of highest risk for mother and newborn. MOH referral protocols were updated, and personnel were trained to use updated protocols during a 4-day one-time training activity aimed at developing EONC knowledge and skills. As it was not possible to add new staff, labor, delivery, and postpartum services were expanded by reorganizing provider work hours and by training and supervising all providers of obstetric and newborn care (residents, midwives, and nurses) in basic and comprehensive EONC.

The network formally integrated TBAs and community health workers (CHWs) with official $\mathrm{MOH}$ recognition to provide essential linkages with the community to increase access and use of EONC among the target population. QI methods were adapted for community-based implementation and used to assess and strengthen care and referral from all levels. The TBAs and CHWs were trained to identify maternal and newborn danger signs and risk factors and to refer them to health centers. Together with health center staff and community organizations, TBAs and $\mathrm{CHW}$ created and continually updated community household maps that identified currently pregnant and postpartum women and newborns, including those with risk factors such as advanced maternal age, multi-parity, and prematurity. In each parish, TBAs and CHWs met monthly with health center staff to review the status of pregnant and postpartum women and newborns. They discussed the conditions of those at risk and how to address barriers including transportation, referral, and prompt care seeking. The network placed special emphasis on increasing coverage and quality of early postpartum/postnatal home visits within 48 h by TBAs and/or health center staff.

A weekly radio program prepared by a local communication team was aired in Spanish and Kechwa by seven radio stations that voluntarily contributed to the network. The radio program provided information about healthy behaviors, danger signs, and seeking professional care.

The network established and supported QI teams comprised of parish health center staff, CHWs, and TBAs who met monthly to work on common aims of improving access and quality of EONC services and to review and resolve problems. QI teams were supported at the provincial referral hospital and the five county hospitals. Hospital QI teams included doctors, nurses, midwives, and auxiliary nurses from maternity and newborn services. They met monthly to audit clinical records, calculate quality indicators, and implement rapid improvement cycles using the Plan-Do-Study-Act Model. This mechanism engaged supervision, training, and continual improvement in facilities with clinical, logistical, and administrative process deficiencies. A QI "managerial team" was organized at the provincial $\mathrm{MOH}$ office, with responsibility to collect and aggregate coverage and quality indicators reported by QI teams and use data to support health centers and hospitals to improve care.

\section{Evaluation}

\section{Household Survey}

The Centro de Estudios de Población y Desarrollo Social, a local research organization, conducted baseline (April 2010) and end-line (July 2013) household surveys. These assessed the project's effects in (1) access to and use of intra- and postpartum/ postneonatal care, (2) women's knowledge and practices, and (3) patient-reported quality of care. The survey questionnaire was adapted from the Knowledge, Practice, and Coverage Rapid Core Assessment Tool on Child Health (CATCH) 2008 (11); a USAID Health-Care Improvement Project household survey tool of mothers with children 0-23 months old (unpublished); and a Knowledge, Attitudes, and Practices Survey on maternal and neonatal health (12). The survey targeted mothers with a living child aged less than 24 months in Cotopaxi Province, excluding urban parishes of the capital, Latacunga. A multistage sample was selected. Primary sample units were the seven counties (secondlevel subdivisions) of Cotopaxi distributed proportionate to the counties' population. Secondary sampling units were 30 parishes, proportionate to parish population. Parishes from the primary intervention county, Pujilí, were oversampled at baseline. After excluding census sectors with too few households to identify four or more children under 2 years old and replacing them with neighboring sectors, the number of sectors was selected by simple random sampling. All households in chosen sectors were visited to identify women with children under 24 months. Data were analyzed using difference-in-differences logistic regression controlling for potential confounders.

\section{Facility Chart Reviews}

Facility quality of care was assessed monthly through measurement of quality indicators calculated by facility QI teams using aggregate data extracted from clinical records' reviews. Each month QI teams sampled clinical records by choosing 30 randomly from a list of all records of women who had received antenatal, delivery, and postpartum care in the month. When there were fewer than 30 records for 1 of the services in the month, all the records were chosen. Results were analyzed and used by facility QI teams to identify deficits and continuously improve care and were included in project monitoring reports. Data were analyzed using Pearson chi-square tests.

\section{Simulations of Care by TBAs}

Traditional birth attendants' knowledge and skills for provision of early postpartum and postneonatal care were assessed by observing a sample of TBAs simulating care with an adult "mother actor" and a neonatal mannequin. Approximate every 3 or 4 months all the participating TBAs who had been trained to identify maternal and newborn danger signs and risk factors and to refer them to health centers, and who were participating in periodic meetings 
at health centers, were invited to a 3-day refresher training. At the start of each refresher training, their knowledge and skills level were assessed. Data were extracted and analyzed using Pearson or Fisher's exact two-tailed chi-square tests comparing the first (pre) and last (post) trimester or the first and last measured performance weighted by the number of observations. Provincial government data provided by the Instituto Nacional de Estadística y Censos (INEC or National Institute of Statistics and Census) were used to estimate the proportion of deliveries for each month thus producing month-specific denominators. Change in neonatal mortality between intervention and non-intervention parishes in Cotopaxi provided by the INEC was analyzed using linear regression weighted by the counties' number of annual births.

Comparisons of intervention and non-intervention parishes limited to the rural sample are presented to show changes in access and use of care and counseling as they include the project population and similar rural, neighboring parishes that constitute the comparison group. We analyzed the rural sample parishes for access and use of care considering that the integration of TBAs and CHWs to the formal network of services, an interventions aimed at increasing access and use of services, was implemented at rural parishes. The comparison group was made of geographical neighboring rural parishes with similar populations. The rural sample included $55 \%$ of the total household sample. With a rural baseline sample of 259 women and end-line sample of 237 women, the rural sample had over $99 \%$ power to detect an increase of $50 \%$ in postpartum visits within $48 \mathrm{~h}$ of birth in the intervention group compared with a $30 \%$ increase in the control group, given their respective baseline levels of 52.5 and $70.0 \%$, with a Type I error of 0.05 . A baseline to end-line comparison of the total sample was analyzed to assess change in women's knowledge and practices, as neighboring non-intervention parishes were equally exposed to the project social and behavioral change media campaign. TBA quality of care was assessed quarterly by simulated case observation. Data were analyzed using Pearson's Chi-square tests for proportions.

The study was approved by the CHS Institutional Review Board. ${ }^{1}$

\section{RESULTS}

The end-line intervention sample was more indigenous (42 versus 59\%), and more women's main occupation was farming their own land ( 64 versus $31 \%$, both $p \leq 0.001$, Table 2 ). Across both intervention and control groups, more end line (98\%) than baseline (91\%) survey participants had no or only primary education $(p=0.002)$ in the rural subsample.

\section{Quality of Care}

More women reported receiving counseling on newborn care in the intervention group than the comparison group (baseline $8 \%$, end line 26\%; $p \leq 0.001$ ) (Table 3). Similarly, more postpartum intervention than comparison group women reported being counseled on newborn danger signs (intervention: baseline 12\%, end line 23\%; comparison: baseline $3 \%$, end line $6 \%$, relative increase $p=0.01$ ) and family planning (intervention: baseline $6 \%$, end line $18 \%$; comparison: baseline $3 \%$, end line $4 \%$, relative increase $p=0.01$ ) during home visits. There was no relative change in pregnant women reporting counseling on birth preparedness or danger signs of pregnancy during home visits or in women reporting counseling on breastfeeding, nutrition, or postpartum danger signs during home visits. There was no relative change in mothers reporting counseling on best practices

${ }^{1}$ Center for Human Services/University Research Co., LLC 7200 Wisconsin Avenue, Bethesda, MD, USA.

TABLE 2 | Household survey for baseline and end-line sociodemographic characteristics of intervention and non-intervention parishes.

\begin{tabular}{|c|c|c|c|c|c|c|c|c|c|c|}
\hline & & \multicolumn{4}{|c|}{ Non-intervention } & \multicolumn{4}{|c|}{ Intervention } & \multirow{3}{*}{$\begin{array}{c}\Delta \\
\text { Total } \\
p\end{array}$} \\
\hline & & \multicolumn{2}{|c|}{ Baseline } & \multicolumn{2}{|c|}{ End line } & \multicolumn{2}{|c|}{ Baseline } & \multicolumn{2}{|c|}{ End line } & \\
\hline & & $\%$ & $n$ & $\%$ & $n$ & $\%$ & $n$ & $\%$ & $n$ & \\
\hline \multirow[t]{4}{*}{ Age group (years) } & $15-19$ & 18 & 33 & 18 & 31 & 15 & 43 & 12 & 28 & 0.77 \\
\hline & $20-29$ & 57 & 103 & 57 & 99 & 44 & 124 & 48 & 115 & \\
\hline & 30-39 & 22 & 40 & 23 & 40 & 32 & 89 & 32 & 75 & \\
\hline & $\geq 40$ & 3 & 6 & 2 & 4 & 9 & 24 & 8 & 20 & \\
\hline \multirow[t]{3}{*}{ Education } & None/primary & 45 & 82 & 42 & 74 & 64 & 179 & 63 & 150 & 0.61 \\
\hline & Secondary & 42 & 77 & 47 & 81 & 31 & 86 & 32 & 77 & \\
\hline & College & 13 & 23 & 11 & 19 & 5 & 15 & 5 & 11 & \\
\hline \multirow[t]{4}{*}{ Ethnicity } & White & 6.0 & 11 & 0 & 0 & 6 & 16 & 0.4 & 1 & $\leq 0.001$ \\
\hline & Mestiza & 84 & 152 & 81 & 141 & 50 & 140 & 40 & 96 & \\
\hline & Indigenous & 5 & 10 & 16 & 28 & 42 & 117 & 59 & 140 & \\
\hline & Other & 5 & 9 & 3 & 5 & 2 & 7 & 0 & 1 & \\
\hline \multirow[t]{3}{*}{ Profession } & House-wife & 65 & 118 & 46 & 80 & 45 & 127 & 18 & 43 & $\leq 0.001$ \\
\hline & Agriculture with own property & 7 & 13 & 6 & 11 & 31 & 88 & 64 & 152 & \\
\hline & Other & 28 & 51 & 48 & 83 & 23 & 65 & 18 & 43 & \\
\hline \multirow[t]{4}{*}{ Marital status } & Single & 21 & 39 & 17 & 29 & 18 & 50 & 15 & 36 & 0.13 \\
\hline & Married & 40 & 73 & 59 & 102 & 64 & 178 & 63 & 149 & \\
\hline & Live together & 35 & 64 & 23 & 40 & 16 & 44 & 21 & 50 & \\
\hline & Other & 3 & 6 & 2 & 3 & 3 & 8 & 1 & 3 & \\
\hline
\end{tabular}


and danger signs in pregnancy or birth preparedness counseling in health facility visits.

\section{Access to Care (Rural Household Survey Sample)}

Postnatal visit within first 2 days of birth increased from 70 to $90 \%$ (a 29\% increase relative to baseline) in the comparison group and from 52 to $81 \%$ (a $54 \%$ increase relative to baseline) in the intervention parishes $(p \leq 0.001)$ (Table 3$)$. While the majority of rural comparison group deliveries occurred in facilities and only slightly more than half did in the rural intervention parishes, relatively more intervention group institutional deliveries received an institutional postpartum visit 2 days after delivery ( $p \leq 0.001$ ). Of postpartum complications identified at home and referred for higher level care, none presented in the comparison group, whereas $10 \%$ in the intervention group did so at baseline and $15 \%$ did at end line. This difference was not statistically significant due to the small number of complications.

\section{Women's Knowledge, Home Best Practices, and Satisfaction (Baseline and End-Line Total Household Survey Sample)}

At end line compared to baseline, more mothers could identify at least two routine newborn care best practices (97 versus $83 \%$ ), newborn danger signs (30 versus $83 \%$ ), and immediate drying of the newborn after delivery ( 31 versus $90 \%$, all $p \leq 0.001$, Table 4).

\section{Facility Chart Audits}

Facility quality measures (Table 5) showed consistent improvements in adherence with clinical standards over time for all but treatment of postpartum hemorrhage and newborn sepsis, in which there were few cases. During the first 3 months of

TABLE 3 | Rural household survey for baseline and end line: access and use of care and postpartum counseling.

\begin{tabular}{|c|c|c|c|c|c|}
\hline \multirow[t]{2}{*}{ Access and utilization of care } & \multicolumn{2}{|c|}{ Non-intervention } & \multicolumn{2}{|c|}{ Intervention } & \multirow{2}{*}{$\begin{array}{l}p \text {-Value for } \\
\text { differences }\end{array}$} \\
\hline & Baseline (\%) & End line (\%) & Baseline (\%) & End line (\%) & \\
\hline Institutional delivery & 89 & 86 & 52 & 50 & 0.226 \\
\hline Postnatal visit within first 2 days of delivery & 70 & 90 & 53 & 81 & $<0.001$ \\
\hline Institutional deliveries report postpartum discharge $>2$ days & 3 & 66 & 5 & 75 & $<0.001$ \\
\hline Identified postpartum complications at home & 15 & 14 & 6 & 12 & 0.228 \\
\hline Postpartum complications at home referred & 0 & 0 & 10 & 15 & 0.62 \\
\hline Postpartum home visit, counseling on newborn care & 1 & 6 & 8 & 26 & $<0.001$ \\
\hline Postpartum home visit, counseling on newborn danger signs and treatment & 3 & 6 & 12 & 23 & 0.011 \\
\hline Postpartum home visit, counseling on family planning & 3 & 4 & 6 & 18 & 0.009 \\
\hline
\end{tabular}

TABLE 4 | Household survey for baseline and end-line comparison of maternal knowledge between intervention and non-intervention sites.

\begin{tabular}{|c|c|c|c|c|c|}
\hline \multirow[t]{2}{*}{ Knowledge survey items } & \multicolumn{2}{|c|}{ Non-intervention } & \multicolumn{2}{|c|}{ Intervention } & \multirow{2}{*}{$\begin{array}{l}p \text {-Value for } \\
\text { differences }\end{array}$} \\
\hline & BL (\%) & EL (\%) & BL (\%) & EL (\%) & \\
\hline Can identify $2+$ routine newborn care best practices & 85 & 89 & 83 & 97 & $<0.001$ \\
\hline Newborn danger signs & 21 & 31 & 30 & 83 & $<0.001$ \\
\hline Immediately dry newborn after delivery & 11 & 23 & 31 & 90 & $<0.001$ \\
\hline Establish newborn's skin-to-skin contact with mother & 6 & 16 & 28 & 90 & $<0.001$ \\
\hline Initiate breastfeeding within hour after delivery & 26 & 32 & 35 & 90 & $<0.001$ \\
\hline Umbilical cord care practice & 4 & 4 & 15 & 89 & $<0.001$ \\
\hline Frequent hand washing & 27 & 13 & 22 & 91 & $<0.001$ \\
\hline
\end{tabular}

TABLE 5 | Quality indicators from chart reviews: last compared with first trimester or year.

\begin{tabular}{|c|c|c|c|c|c|}
\hline \multirow[t]{2}{*}{ Adherent with clinical standards } & \multicolumn{2}{|c|}{ First trimester } & \multicolumn{2}{|c|}{ Last trimester } & \multirow[t]{2}{*}{$p$} \\
\hline & $\%$ & $n$ & $\%$ & $n$ & \\
\hline Facility first ANC visits at rural subcenters & 56 & 303 & 90 & 602 & $\leq 0.001$ \\
\hline Ambulatory postpartum facility visits at rural subcenters & 68 & 78 & 98 & 267 & $\leq 0.001$ \\
\hline Ambulatory newborn facility visits at rural subcenters & 73 & 77 & 88 & 170 & $\leq 0.001$ \\
\hline Hospital deliveries with active management of the third stage of labor & 68 & 57 & 97 & 147 & $\leq 0.001$ \\
\hline Hospital administration of antenatal corticosteroids in premature births & 67 & 3 & 93 & 27 & 0.16 \\
\hline Hospital management of premature rupture of membranes & 0 & 1 & 100 & 2 & NA \\
\hline Hospital immediate essential newborn care & 13 & 38 & 50 & 147 & $\leq 0.001$ \\
\hline Hospital postpartum hemorrhage management & 100 & 2 & 86 & 7 & 0.57 \\
\hline Hospital newborn sepsis case management & 100 & 5 & 67 & 3 & 0.18 \\
\hline
\end{tabular}

Intervention parishes. 
intervention, $56 \%$ of health centers' first antenatal visit sessions met clinical standards compared with $90 \%$ during the final 3 months\% ( $p \leq 0.001$ ). At the first and last trimesters of intervention, 68 versus $98 \%$ of health center outpatient maternal postpartum visits met clinical standards; in hospitals, this increased from 0 to $81 \%$ (both $p \leq 0.001$ ). In health centers, $73 \%$ during the first 3 months and $88 \%$ during the last 3 months of newborn facility ambulatory visits met clinical standards $(p \leq 0.001)$. Other facility inpatient indicators were only reported by area hospitals. At the first and last intervention trimesters, 68 versus $97 \%$ of facility deliveries received active management of the third stage of labor, and 13 versus $50 \%$ of facilities were fully compliant with inpatient immediate ENC standards $(p \leq 0.001)$. The difference in the number of first ANC visits and quality of care indicators reflects the large divergence in where and when people seek care. Most institutional postpartum and postnatal visits occurred in primary health centers, not hospitals.

\section{Assessment of TBA Knowledge and Skills through Simulations}

Assessment of TBA knowledge and skills show consistent improvements between the first and last project implementation trimesters (Table 6). As assessed by simulation observation, $2 \%$ of TBAs met standards of maternal postpartum physical examination in the first 3 months and $17 \%$ in the last 3 months assessed, and $54 \%$ of TBAs met standards of neonatal immediate postnatal physical examination in the first 3 months compared with $77 \%$ in the last 3 months assessed (Table 6, both $p \leq 0.001$ ).

\section{Neonatal Mortality}

The intervention group parishes' newborn mortality rates declined from 5.5/1,000 live births to 4.2/1,000 live births between 2009 and 2012, compared with a slight increase from $4.5 / 1,000$ live births to $4.7 / 1,000$ live births in the control group $(p \leq 0.001)$.

\section{DISCUSSION}

This project dedicated about 2 years to establish a comprehensive, integrated provincial-level vertical and horizontal network that improved access to, quality, use, and provision of EONC for the most impoverished, indigenous counties of Cotopaxi, Ecuador.
By supporting innovative, integrated, and community-oriented programing that aligned formal and informal health systems in the Province, the project transformed a multitude of isolated services and resources into a coordinated, cooperative entity. This appeared in line with reports of similar private-public partnerships in other resource-constrained settings (7-9). TBAs in Ecuador and other countries have been marginalized from the formal health system.

This study evaluated the intervention to improve birth attendant performance with the application of QI methods implemented in the EONC network. Our data support the value of formally recognizing and integrating TBAs into EONC services, consistent with observations that when integrated into a healthcare system, TBAs can play an integral role in improving EONC services and maternal and newborn health (13-15). Moreover, through the creation of an EONC network, the project bridged profound gaps among fractured and isolated public and nongovernmental institutions aligning formal and informal health systems and linking science-based health care with traditional and culturally responsive procedures. EONC was tailored to be implemented in a three-level network of services - parish health centers, district, and provincial hospitals - each one with its specific responsibilities and an effective referral system. QI methods were implemented at each level in the EONC network. Application of these principles resulted in an increase of access to and quality of EONC services. It greatly contributed to improving postpartum and neonatal care within the first 2 days of delivery, an outcome that likely contributed to neonatal survival improvement. While geographically and temporally limited randomized controlled trials have successfully mobilized communities to improve maternal and neonatal health $(2,4,5)$, our project demonstrates impact for mothers and newborns at a time when outside support for health in Ecuador and Latin America was waning.

The Cotopaxi Project achieved its primary objective to increase the proportion of mothers and newborns receiving postpartum/ postnatal care within $48 \mathrm{~h}$ of birth. The improvement was large considering the relative poverty and marginalization of the intervention group and the fact that the intervention was only fully implemented for 2 years in Pujilí and only 1 year in the other intervention parishes. This appears to be mostly attributable to improving postpartum visits in newborns delivered in institutions. A tradition of 40 days postpartum bed rest exists among

TABLE 6 | Assessment of TBA knowledge and skills based on observation of simulated postpartum exam.

\begin{tabular}{|c|c|c|c|c|c|}
\hline & \multicolumn{2}{|c|}{ First year } & \multicolumn{2}{|c|}{ Last year } & \multirow[t]{2}{*}{$p$} \\
\hline & $\%$ & $n$ & $\%$ & $n$ & \\
\hline \multicolumn{6}{|l|}{ TBAs can cite } \\
\hline Two or more pregnancy danger signs & 94 & 313 & 100 & 49 & 0.029 \\
\hline$\geq$ Birth preparedness actions & 82 & 320 & 98 & 49 & 0.004 \\
\hline Two or more postpartum danger signs & 91 & 312 & 100 & 49 & 0.024 \\
\hline Two or more newborn danger signs & 86 & 311 & 98 & 49 & 0.017 \\
\hline Two or more newborn best practices & 91 & 312 & 100 & 49 & 0.024 \\
\hline TBA adherence with maternal postpartum physical examination standards (observation of simulation) & 1 & 81 & 17 & 29 & 0.001 \\
\hline TBA adherence with newborn immediate postnatal physical examination standards (observation of simulation) & 54 & 81 & 77 & 29 & 0.042 \\
\hline
\end{tabular}


the indigenous population of Cotopaxi, which may explain why there are many fewer ambulatory postpartum and postnatal than first ANC visits.

Improvement in the newborn care quality indicator was smaller than expected because 1 of the 11 criteria to completely adhere with newborn care norms, prophylaxis to prevent neonatal ocular infection, is unreliable and underestimates compliance because the norms recommended a specific brand of medication that was unavailable for many years. Suitable substitutes were used, but some clinics report compliance with this indicator literally (having not used the specified brand) while others did so figuratively (having used an effective alternative).

The differences in demographic characteristic and sampling may have underestimated the effects presented. Neither baseline nor end-line surveys were to include parish townships, yet both did, therefore to best represent the intervention area and improve the similarity of the groups, the analyses excluded parish townships. Reducing the sample size underestimated the statistical significance of some observed effects.

In this setting during the period of the intervention, there was no other project being implemented to attribute the changes seen apart from the one described here. We feel that the use of a control group accounted adequately for the secular trend of improvement that may have been occurring even in nonintervention sites.

While the project had little influence on the overall proportion of institutional deliveries, these results may simply reflect the fact that the end-line sample was distinctly more indigenous, poor, and vulnerable than the baseline sample. This contention is supported by the data. The Ecuadorean $\mathrm{MOH}$ has formally adopted the model with a dedicated budget and personnel to scale it up nationally. With the Ministry's rollout, the EONC network model will continue to be adapted to the heterogeneous

\section{REFERENCES}

1. Centro de Estudios de Población y Desarrollo Social. Informe Final: Endemain. Quito, Ecuador: CEPAR (2005).

2. Manandhar DS, Osrin D, Shrestha BP, Mesko N, Morrison J, Tumbahangphe $\mathrm{KM}$, et al. Effect of a participatory intervention with women's groups on birth outcomes in Nepal: cluster-randomised controlled trial. Lancet (2004) 364(9438):970-9. doi:10.1016/S0140-6736(04)17021-9

3. Kerber KJ, de Graft-Johnson JE, Bhutta ZA, Okong P, Starrs A, Lawn JE. Continuum of care for maternal, newborn, and child health: from slogan to service delivery. Lancet (2007) 370(9595):1358-69. doi:10.1016/ S0140-6736(07)61578-5

4. Kumar V, Mohanty S, Kumar A, Misra RP, Santosham M, Awasthi S, et al. Effect of community-based behaviour change management on neonatal mortality in Shivgarh, Uttar Pradesh, India: a cluster-randomised controlled trial. Lancet (2008) 372(9644):1151-62. doi:10.1016/S0140-6736(08) 61483-X

5. Tripathy P, Nair N, Barnett S, Mahapatra R, Borghi J, Rath S, et al. Effect of a participatory intervention with women's groups on birth outcomes and maternal depression in Jharkhand and Orissa, India: a cluster-randomised controlled trial. Lancet (2010) 375(9721):1182-92. doi:10.1016/S0140-6736(09) 62042-0

6. Hermida J, Salas B, Sloan NL. Sustainable scale-up of active management of the third stage of labor for prevention of postpartum hemorrhage in Ecuador. Int J Gynaecol Obstet (2012) 117(3):278-82. doi:10.1016/j.ijgo.2012. 01.017 settings within Ecuador. Having been tested only in Ecuador, a middle-income country, the model should be adapted and evaluated in other settings, particularly in settings where significant disparities persist in maternal and newborn health outcomes and access to and quality of EONC services among disadvantaged populations.

\section{CONCLUSION}

This USAID-funded project in Cotopaxi established a comprehensive, coordinated, and sustainable provincial-level network of health services and strengthened links between community, primary, and hospital health care. There was substantive improvement in access to, quality, use, and provision of essential obstetric and neonatal care and survival. The $\mathrm{MOH}$ in Ecuador is scaling up the model nationally.

\section{AUTHOR CONTRIBUTIONS}

$\mathrm{JH}$ and $\mathrm{KH}$ conceived the intervention and led in organizing its implementation; EB and NS conceived the evaluation, performed the analysis, and took the lead in writing the manuscript; MC, DG, JF, and XG assisted in implementing the evaluation, organizing and executing data collection, and provided input to all sections of the manuscript. All the authors approved the final version of the manuscript. EB and $\mathrm{JH}$ took primary responsibility for the responses to the reviewers' comments.

\section{FUNDING}

The Cotopaxi, Ecuador EONC Project was funded by USAID's Child Survival and Health Grants Program under the terms of grant number GHS-A-00-09-00008-00.

7. Bustreo F, Harding A, Axelsson H. Can developing countries achieve adequate improvements in child health outcomes without engaging the private sector? Bull World Health Organ (2003) 81(12):886-95.

8. Marek T, O'Farrel C, Yamamoto C, Zable I. Trends and opportunities in public-private partnerships to improve health service delivery. Africa Region Human Development Series. Washington: World Bank (2005): 1-89.

9. Prata N, Montagu D, Jefferys E. Private sector, human resources and health franchising in Africa. Bull World Health Organ (2005) 83(4):274-9.

10. Villacís B, Carrillo D. Estadística demográfica en el Ecuador: diagnóstico y propuestas. Quito, Ecuador: Nacional de Estadística y Censos (INEC) (2011).

11. Child Survival Technical Support Project and the CORE Monitoring and Evaluation Working Group. Knowledge, Practices and Coverage Survey, 2000+. Washington: CORE Group (2008).

12. Child Survival Technical Support Project and the CORE Monitoring and Evaluation Working Group. Knowledge, Practices and Coverage Survey Training Curriculum. Washington: CORE Group (2004).

13. Koblinsky M, Matthews Z, Hussein J, Mavalankar D, Mridha MK, Anwar I, et al. Going to scale with professional skilled care. Lancet (2006) 368(9544):1377-86. doi:10.1016/S0140-6736(06)69382-3

14. Pagel C, Lewycka S, Colbourn T, Mwansambo C, Meguid T, Chiudzu G, et al. Estimation of potential effects of improved community-based drug provision, to augment health-facility strengthening, on maternal mortality due to post-partum haemorrhage and sepsis in sub-Saharan Africa: an equity-effectiveness model. Lancet (2009) 374(9699):1441-8. doi:10.1016/ S0140-6736(09)61566-X 
15. Sibley LM, Sipe TA, Barry D. Traditional birth attendant training for improving health behaviours and pregnancy outcomes. Cochrane Database Syst Rev (2012) 8:CD005460. doi:10.1002/14651858.CD005460.pub3

Conflict of Interest Statement: The authors declare that the research was conducted in the absence of any commercial or financial relationships that could be construed as a potential conflict of interest.
Copyright (c) 2016 Broughton, Hermida, Hill, Sloan, Chavez, Gonzalez, Freire and Gudino. This is an open-access article distributed under the terms of the Creative Commons Attribution License (CC BY). The use, distribution or reproduction in other forums is permitted, provided the original author(s) or licensor are credited and that the original publication in this journal is cited, in accordance with accepted academic practice. No use, distribution or reproduction is permitted which does not comply with these terms. 